\title{
X-Ray Powder Diffraction Data-Identification and Structure Elucidation of Unknown Stone-Rietveld Refinement Approach
}

\author{
Munusamy Baskar $^{1 *}$, Anju Patania ${ }^{2}$ \\ ${ }^{1}$ Central Forensic Science Laboratory, Directorate of Forensic Science Services, Bhopal, India \\ ${ }^{2}$ Central Forensic Science Laboratory, Directorate of Forensic Science Services, Chandigarh, India \\ Email: *munubas@yahoo.com
}

How to cite this paper: Baskar, M. and Patania, A. (2020) X-Ray Powder Diffraction Data-Identification and Structure Elucidation of Unknown Stone-Rietveld Refinement Approach. Journal of Biophysical Chemistry, 11, 51-61.

https://doi.org/10.4236/jbpc.2020.114005

Received: October 28, 2020

Accepted: November 27, 2020

Published: November 30, 2020

Copyright $\odot 2020$ by author(s) and Scientific Research Publishing Inc. This work is licensed under the Creative Commons Attribution International License (CC BY 4.0).

http://creativecommons.org/licenses/by/4.0/

\begin{abstract}
A dark and lead to silver grey soft irregular-shaped with heavy weight stone has been analysed as a part of research work for determining the components of the stone thereby leading to identify curiously to pinpoint whether the stone is in a category of gemstone, radioactive elements, raw or ingredients for making a powerful bomb or otherwise. In addition to the physical and optical parameters measured such as specific gravity, hardness, luster, transparency, cleavage, streak and other associated minerals for identification of unknown stone, Powder X-ray diffraction (PXRD) is one of the primary techniques in identification of minerals to examine the physico-chemical make-up of unknown materials, and has also been employed using Philips, DY993 X-ray Powder Diffractometer. The diffraction spectrum has been measured with the proportional counter in the $2^{\circ}$ to $100^{\circ}$ range at room temperature $300 \mathrm{~K}$. This study reveals that the stone is not a category of precious stone; instead it is a category of mineral deposition, $\mathrm{PbS}$, Galena.
\end{abstract}

\section{Keywords}

Precious Stone, Galena (PbS), Polycrystalline, Mineral, Titanium, Copper Target

\section{Introduction}

Powder X-ray Diffraction (PXRD) is a decisive tool in identifying polycrystalline materials by their unique diffraction patterns and is one of the best common analytical methods for nondestructive technique which provides information on structures, phases, texture, and other structural parameters of grain size, crystal- 
linity, strain for characterizing crystalline materials about the composition of the solid crystalline material and are especially significant for the analysis of solid materials in forensic science for the forensic identification of unknown solid [1]. High-resolution PXRD patterns provide good data to determine the phase composition of crystalline samples, yet morphology and particle shape/size can induce severe preferential orientation that can degrade the utility of XRD powder data. Indeed the morphology of a stone can even induce to adopt the X-ray diffraction technique in identification of unknown solid samples [2]. Very small changes in the X-ray powder diffraction pattern may appear as a new peak(s) or shoulders or shifts in the peak position due to impurity of the solid sample or some other well-defined crystalline material adhered with the very high percentage of the solid sample can imply the presence of a new form of crystal components [3] [4]. X-ray diffraction is the principle method of characterization and its simplicity and advantages of the powder diffraction technique can help to identify the unknown material after comparing with the diffraction spectrum of the specimen material provided by the Joint Committee for Powder Diffraction File (JCPDF) [5] inbuilt in the software and licensed.

In this article, a dark and lead to silver grey soft irregular-shaped stone has been studied and identified for forensic purpose in order to reveal whether the stone is a kind of gemstone category? If not, what kind of stone it is and its components.

At large, structure determination from X-ray powder data and single crystal data may not be the new approach. However, handling the X-ray powder data to identify the unknown stone by determining its molecular structure through Rietveld method [6] could be the beginning of the history of Forensic Science.

The structural determination and its refinement of poly-crystals are being routinely carried out using X-ray powder diffraction with crystallographic software based on the Rietveld method [6] [7].

\section{Methods}

\subsection{Physical Properties}

The stone has been broken into pieces among which representative stone particles have been selected for measuring various optical parameters such as cleavage, hardness, specific gravity etc. The stones were opaque and brittle in nature. The stone was even heavy in weight as compared to any other metallic materials and having deposited a bluish tint on it. Some meager quantity of small sized whitish patches as a streak in a round shape has been observed on the stone. This whitish patch may mislead the analyst as a rock crystal. In this study, the stone was first subjected to measure its specific gravity then morphological identification. The morphology of the stone is as depicted in Figure 1. The decomposition temperature has been accessed as greater than $400^{\circ} \mathrm{C}$ using a temperature controlled digital furnace. The stone is dissolved in analytically pure $\mathrm{HNO}_{3}$ and hot concentrated $\mathrm{HCl}$. 


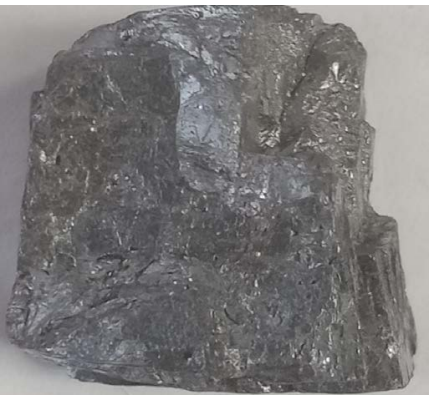

(a)

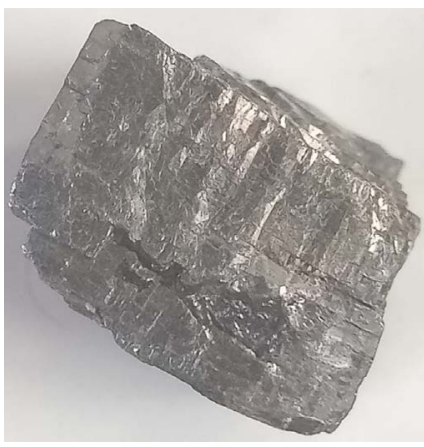

(c)

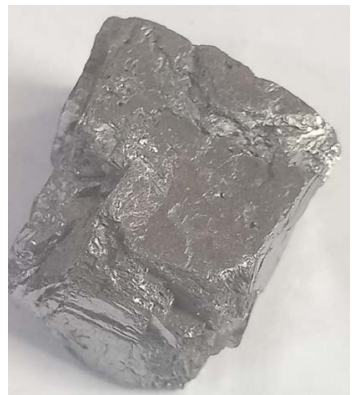

(b)

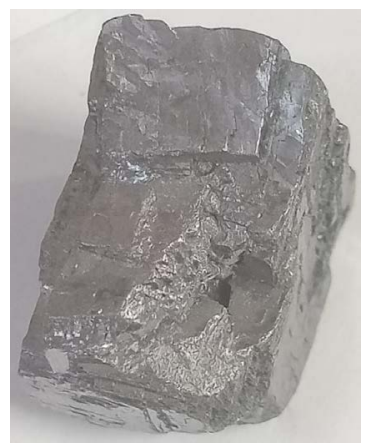

(d)

Figure 1. Morphology of various orientation of the unknown stone.

\subsection{Physical Examination}

The stone was cut into approximately equal size and its specific gravity was determined using the immersion method and averaged for five repeated values as $7.5 \mathrm{~g} / \mathrm{cm}^{3}$. The preliminary study such as the specific gravity, luster, shape, colour and morphology etc., data of the stone made intuition to lead further examination in order to identify the unknown.

\subsection{Data Collection}

The stone has been broken gently into pieces from a solid lump of about $1 \mathrm{~kg}$ and then subjected to make a powder using the planetary ball mill, Retsch-PM100, for a grain size suitable for scanning under X-ray powder diffractometer. The ground powder sample was sieved with a sieve Mesh No.270 $(0.053 \mathrm{~mm}$ or 0.0021 inches or 53 microns). The procedure was repeated till the particle size comes approximately equal to $1-5 \mu \mathrm{m}$ in order to get the sharp and continuous $\mathrm{X}$-ray diffraction peaks. Approximately, $0.2 \mathrm{~g}$ of powder particle passed through the sieve No. 270 was tightly packed into the titanium sample stub having a cavity of $13 \mathrm{~mm}$ diameter and $3 \mathrm{~mm}$ depth and then the sample was smoothed to make it to bring even surface around all over the sample with a glass slide. The sample loaded in a titanium sample stub has been carefully mounted on the sample chamber in X-ray diffractometer along the optical axis of the goniometer in the Bragg-Brentano geometry. The diffractometer parameters during the data collection were set at $45 \mathrm{kV}$ and $30 \mathrm{~mA}$ with a Cu radiation $(\lambda=1.54056 \AA)$. The diffractometer had a proportional counter. The goniometer position was fixed 
and allowed for $2 \theta$ to move from $2^{\circ}$ to $100^{\circ}$. The step size for moving the goniometer was set as $0.02^{\circ}$ at a speed of $2^{\circ}$ per minute. While scanning the sample, the goniometer moves through its range i.e. from $2^{\circ}$ to $100^{\circ}$ and stopping at each step by the allotted time. The raw scanning using the X-ray powder Diffractometer of the unknown stone powder is as shown in Figure 2. The X-ray counts at each step were saved in a file for further analysis for striping out $K \alpha$ radiation and smoothing the X-ray spectrum with a weighted moving average and finally a diffractogram like the one shown in Figure 3 is displayed. X-ray diffracted data were collected at a room temperature of $300 \mathrm{~K}$ using a Panalytical X-PERT PRO, DY993 X-ray Powder Diffractometer.

The analysis has been constrained to a total of $100 \%$ relative intensity which will be collected from each peak. The $d$ spacing and the intensity data has been compared to similar data in the Joint Committee on Powder Diffraction Standards (JCDPS) provide with the software in the Philips (Panalytical) X-PERT PRO, Dy993 XRPD.

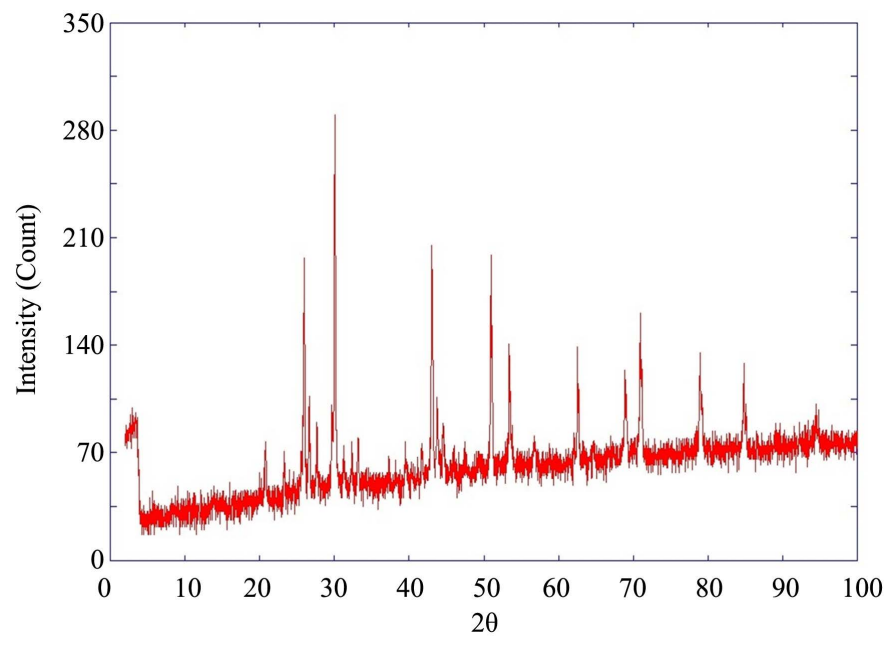

Figure 2. XRD pattern of unknown stone.

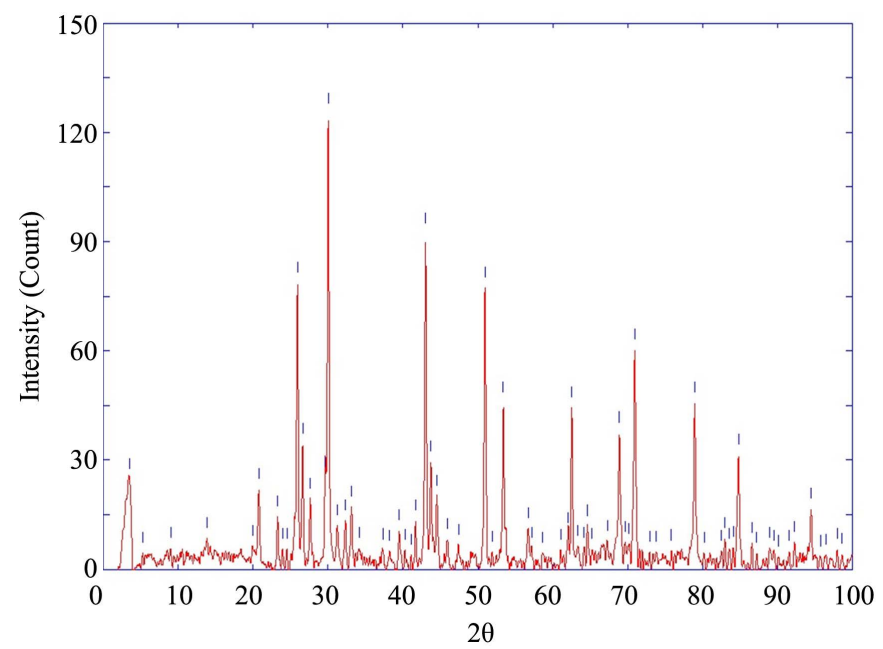

Figure 3. Powder spectrum after Ka removal and indexation. 
*The wavelengths $(\AA)$ for copper radiation are:

$\begin{array}{lll}\text { K-Alpha1 }(\AA) & : & 1.54056 \\ \text { K-Alpha2 }(\AA) & : & 1.54439 \\ \text { K-Alpha2/K-Alpha1 ratio } & : & 0.50000 \\ \text { K-Beta }(\AA) & : & 1.39222 \\ \text { Used wavelength } & : & \text { K-Alpha1 }\end{array}$

\section{Results and Discussion}

X-ray diffraction patterns were obtained using a Philips DY993, X-PERT PRO $\mathrm{X}$-ray Powder Diffractometer equipped with proportional detector. The sample was exposed with the X-rays produced under the copper target $(1.5418 \AA)$ and diffracted data was collected through the proportional counter. The $2 \theta$, d, relative intensity etc. values have been obtained. Accordingly, the spectrum pattern obtained from the X-ray powder diffraction has been analysed eliminating the $\mathrm{k} \alpha$ values and then the peak has been searched using the software X-PERT PRO ver 3.0. Phase identification was performed using the software, search Match ver 3.01, from Philips and the PDF database file version 2003 from ICDD.

On the basis of the JCPDS, the peaks were indexed and analysed for the identification of minerals the stone sample contains. The Hanawalt procedure, prevalently adapted to the diffractometric technique [8] [9] [10] [11] has been used in identification of mineral contents in the stone sample and then by searching the crystalline component phases of a mixture or unknown in its X-ray diffraction pattern using PCPDFWIN software which can retrieve/display for accessing records from the search from JCPDS having 60,000 compounds. Indexation of the powder pattern and calculation of the lattice constant(s) have been carried out manually by using the method of $\sin ^{2} \theta$ and experimental $d$ values respectively. Alpha-2 Stripping, Background subtraction and Indexation has also been carried out using the procedure Treor incorporated in the POWDER X [12] software for an intermediate check if the background subtraction and indexation do compromise with the Treor inbuilt with the Fullprof [13] suite of programs. The indexing of this pattern is shown in Table 1.

\subsection{Rietveld Refinement}

The data thus obtained from POWDER X has been subjected to Rietveld refinement using Fullprof Suit of Programs [13], General Structure Analysis System (GSAS) [14] software packages. The refinement was conducted based on the model for the crystal structure, peak profile, background intensities, lattice constants, atomic position etc. the refinement method based on the likelihood estimation of fluorapatite $\mathrm{Ca}_{3}\left(\mathrm{PO}_{4}\right)_{3} \mathrm{~F}$ [15] [16], anglesite $\mathrm{PbSO}_{4}$ [17] and barite $\mathrm{BaSO}_{4}[18]$ have been carried and demonstrated out using DBWS, Fullprof and RIETAN-FP software packages [19]. The structure of a novel layered aluminum methylphosphonate, $\mathrm{Al}_{2}\left(\mathrm{CH}_{3} \mathrm{PO}_{3}\right)_{3}$, has been solved from X-ray powder diffraction data by simulated annealing of five independent structural sub-units, revealing a combination of four-and five-fold coordinated aluminums within the 
Table 1. Measurement parameters X-PERT PRO, Dy993 XRPD.

\begin{tabular}{|c|c|c|}
\hline Scan axis & $:$ & Gonio; PW3050 (Theta/2Theta) \\
\hline Incident beam radius $(\mathrm{mm})$ & $:$ & 200 \\
\hline Take-off angle $\left(^{\circ}\right)$ & : & 6.0 \\
\hline Scan mode & $:$ & Continuous \\
\hline Start angle $\left({ }^{\circ}\right)$ & : & 5.0 \\
\hline End angle $\left({ }^{\circ}\right)$ & : & 100.0 \\
\hline Step size $\left({ }^{\circ}\right)$ & $:$ & 0.020 \\
\hline Time per step (s) & : & 0.25 \\
\hline Scan speed $(\% / s)$ & $:$ & 0.08 \\
\hline Number of steps & : & 4750 \\
\hline Total time(h:m:s) & : & 00:19:48 \\
\hline $\mathrm{X}$-ray tube & : & PW3373/00 Cu LFF \\
\hline Soller slit & : & Soller 0.04 rad. (MPD) \\
\hline Sample stage & $:$ & PW3072/00 Bracket \\
\hline Focus & : & Line \\
\hline Min. 2 Theta angle $\left({ }^{\circ}\right)$ & : & -2.754 \\
\hline Max. 2 Theta angle $\left({ }^{\circ}\right)$ & $:$ & 167 \\
\hline Min. Omega angle $\left({ }^{\circ}\right)$ & : & -3.262 \\
\hline Max. Omega angle $\left({ }^{\circ}\right)$ & : & 180.0 \\
\hline Optic number & : & 1 \\
\hline offset $\left({ }^{\circ}\right)$ & : & 0.01 \\
\hline Radius (mm) & : & 200 \\
\hline Detector & & PW3011 Miniprop \\
\hline
\end{tabular}

inorganic lamellae that is unique for this kind of solid [20]. The X-ray powder diffraction pattern of $\mathrm{Fe}_{2} \mathrm{GeSe}_{4}$, semi-conducting compound, has been recorded in room temperature and evaluated and the structure refinement was carried out using the Rietveld method [21]. Structure of Lead Chalcogenides $\mathrm{PbX}(\mathrm{X}=\mathrm{S}$, Se, $\mathrm{Te})$ was carried out with the single crystal X-ray diffraction data [22] using the full-matrix least-squares program RADIEL [23].

The crystallographic properties have been uniformly maintained in both the two software packages for getting the results from the refinement of the data. The structure, thus, obtained is as summarized below.

\subsection{Fullprof Suit}

The software, Fullprof-Suit of programs, was employed for refinement of the powder data thus obtained from the X-ray powder diffractometer as described. The matching .cif file as suspected was chosen from Crystallographic Open Data Base [24] along with input raw data in the .rd format obtained from the X-ray 
diffractometer. The procedure as described in the Fullprof user manual was followed for refining the crystallographic parameters such as unit cell values, atomic coordinates, atomic displacements, background of the spectrum, the $\mathrm{K} \alpha$ removed original powder data of the spectrum, asymmetric data sets etc.

The background information was refined using linear interpolation between a set background points with refinable heights. The pattern contribution information for phase and the peak shape were refined under X-ray and Pseudo-Voight function respectively. The unit cell parameters were converged as, $\mathrm{a}=\mathrm{b}=\mathrm{c}=$ $5.93557 \AA, \alpha=\beta=\gamma=90^{\circ}$.

\subsection{General Structure Analysis Software (GSAS)}

The refinement was also carried out using the software GSAS with the Raw XRD data and CIF file downloaded from open crystallographic database. The weighted $\mathrm{R}$ value is converged as $13.38 \%$ with $\mathrm{R}$ background $17.45 \%$. The unit cell parameters were, $\mathrm{a}=\mathrm{b}=\mathrm{c}=5.5 .97822 \AA, \alpha=\beta=\gamma=90^{\circ}$. The limit values refined is from $2^{\circ}$ to $100^{\circ}$ and the converged structure is placed in van der walls model (VDW) model in Figure 4 and Figure 5.

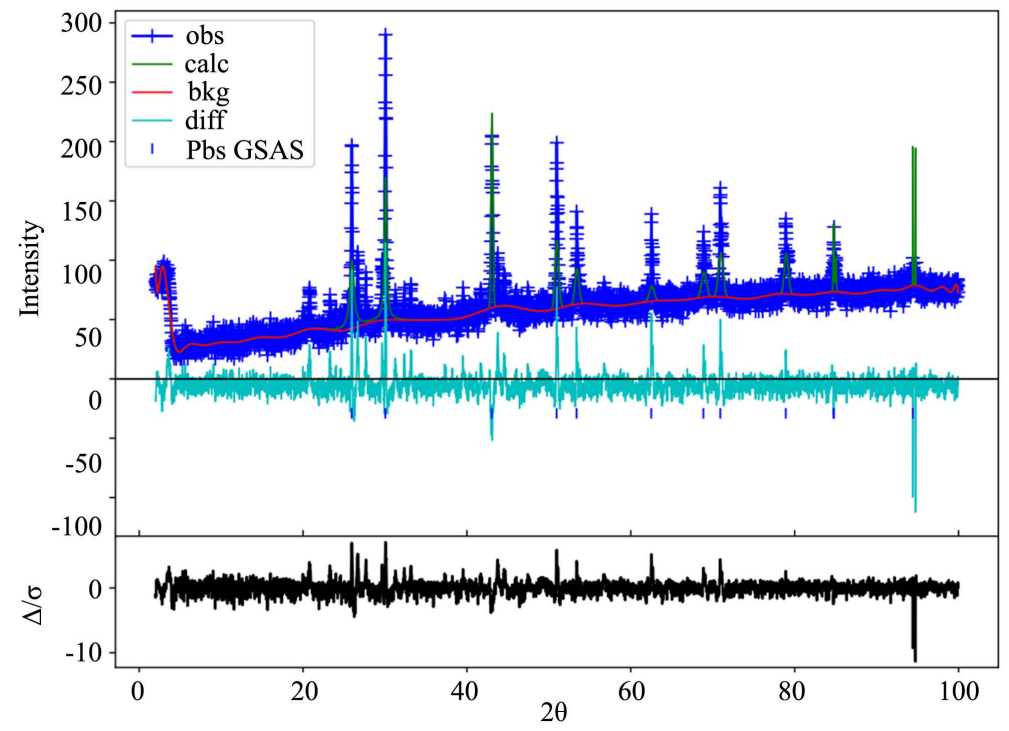

Figure 4. Results of Rietveld refinement using GSAS.

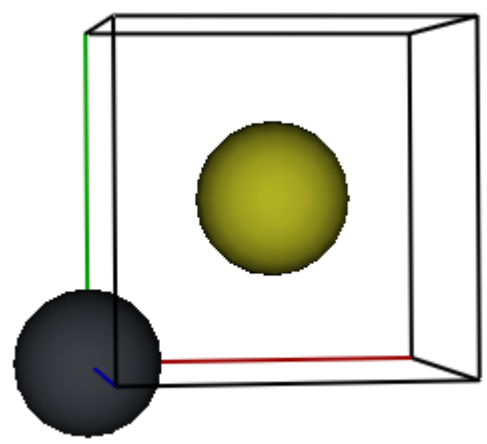

Figure 5. VDW model of PbS structure Rietveld refinement using GSAS. 
The image of the stone is agglomerated composite particles with a cubic crystal and shapes of perfect cleavage in Figure 1. Figure 3 shows the pattern of $\mathrm{PbS}$ crystal in composite with the space group Fm $3 \mathrm{~m}$ in face centered cubic crystal. The unit cell parameters of the unknown is a $=5.935 \AA$ and $\alpha=\beta=\gamma=90^{\circ}$. The spectrum shows the diffraction peaks for PbS in Figure 3, Figure 6 and Figure 7 at $2 \theta$ values are given in Table 2 .

The cell lattice constant of the PbS crystallites was determined from the XRD pattern as 5.935 which is the same as standard phase PbS (5.94 $\AA$ ) reported [25] as experimentally proved from the XRD results on the Galena synthesized. From the calculations of the indices [26] hkl presented in Table 2 the unit cell is falling under cubic FCC lattices and the same values have been calculated by the PowderX Diffraction analysis software.

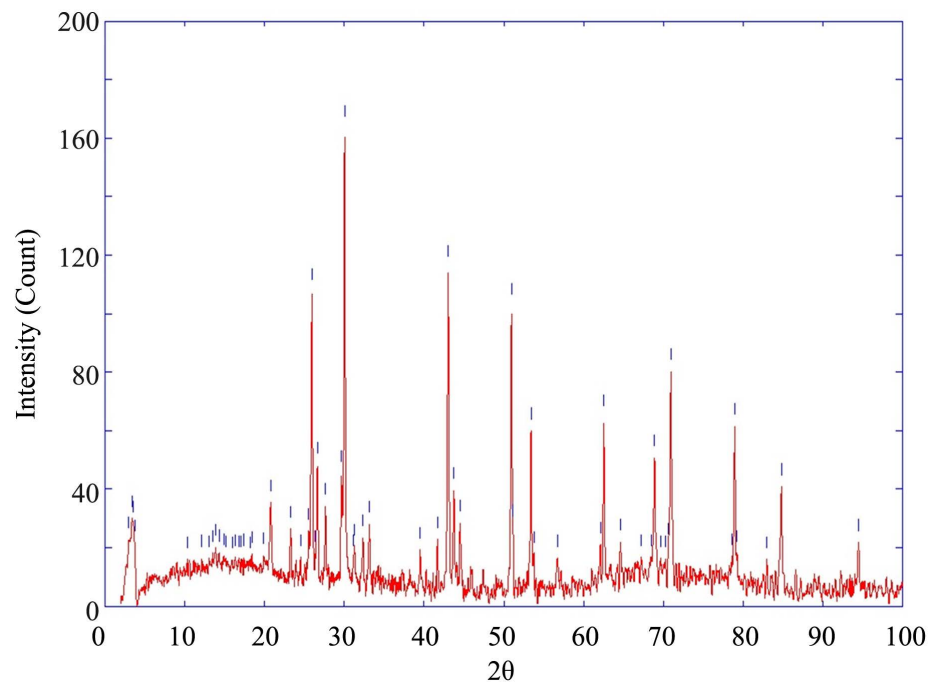

Figure 6. Powder spectrum after Ka removal, background correction and indexation.

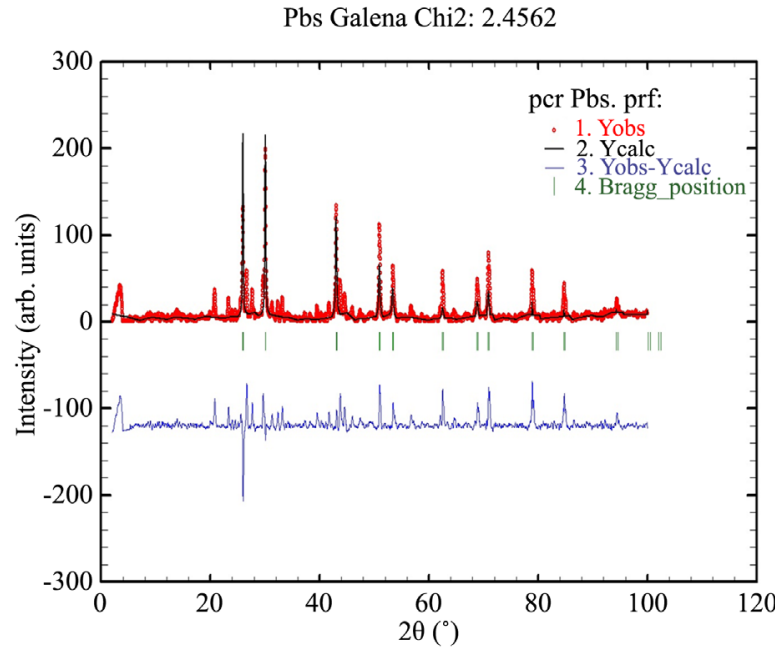

(a)

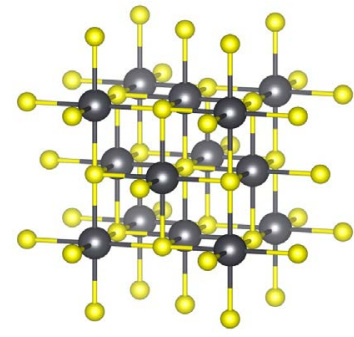

(b)

Figure 7. Results of Rietveld refinement using Fullprof suite determining the PbS structure. (a) Spectrum of completed Rietveld refinement; (b) Structure of the PbS. 
Table 2. The prominent peaks selected from the original spectrum.

\begin{tabular}{cccccccccccc}
\hline 2 Theta & $\theta$ & Radians & $\sin \theta$ & $\sin ^{2} \theta$ & Ratio $1 * 3$ & $\mathrm{~d}(\AA)$ & hkl & Height & Area & FWHM \\
\hline 25.984 & 12.992 & 0.226638 & 0.224703 & 0.050491 & 3 & 3.42629 & 111 & 108.0 & 1478.4 & 0.2828 \\
30.092 & 15.046 & 0.262469 & 0.259466 & 0.067323 & 4.000038 & 2.96725 & 311 & 45.3 & 3280.3 & 0.3304 \\
43.076 & 21.538 & 0.375718 & 0.366941 & 0.134646 & 8.000109 & 2.09816 & 200 & 167.9 & 2335.1 & 0.2941 \\
50.997 & 25.4985 & 0.444807 & 0.430284 & 0.185144 & 11.00053 & 1.78932 & 220 & 117.7 & 1880.1 & 0.3240 \\
53.440 & 26.72 & 0.466116 & 0.44942 & 0.201978 & 12.00073 & 1.71314 & 311 & 96.5 & 1668.2 & 0.3505 \\
62.556 & 31.278 & 0.545627 & 0.518954 & 0.269314 & 16.00155 & 1.48363 & 222 & 54.9 & 995.9 & 0.3723 \\
68.912 & 34.456 & 0.601066 & 0.565522 & 0.319815 & 19.00213 & 1.36147 & 400 & 48.2 & 876.5 & 0.3559 \\
70.867 & 35.4335 & 0.618118 & 0.579502 & 0.335823 & 19.95325 & 1.32699 & 331 & 41.8 & 983.4 & 0.4677 \\
78.969 & 39.4845 & 0.688785 & 0.6356 & 0.403987 & 24.0033 & 1.14210 & 420 & 68.0 & 1534.3 & 0.4403 \\
84.822 & 42.411 & 0.739836 & 0.674167 & 0.454501 & 27.00465 & 1.14210 & 422 & 48.9 & 1123.8 & 0.4745 \\
94.487 & 47.2435 & 0.824137 & 0.733962 & 0.5387 & 32.00739 & 1.04908 & 440 & 35.4 & 863.7 & 0.5003 \\
\hline
\end{tabular}

\section{Conclusions}

This study has been used to identify and confirm the unknown stone which was subjected to identify for the forensic purpose. The data collected using the powder X-ray diffraction was subjected to analysis with the Rietveld techniques with the help of two crystallographic software packages, in order to cross-check the results, such as Fullprof and GSAS both ended elucidating the similar molecular structure of the unknown stone as $\mathrm{PbS}$, Galena by converging both the unit parameters of unknown stone $\mathrm{a}=\mathrm{b}=\mathrm{c}=5.93557, \alpha=\beta=\gamma=90^{\circ}$ and $\mathrm{a}=\mathrm{b}=\mathrm{c}$ $=5.97822, \alpha=\beta=\gamma=90^{\circ}$ respectively and also their atomic positions with Vander Waals radii and temperature factors are:

\begin{tabular}{cccccc}
\hline \multirow{2}{*}{ Atoms } & \multicolumn{3}{c}{ Coordinates } & \multirow{2}{*}{ Uiso } & \multirow{2}{*}{ VDW radii } \\
\cline { 2 - 4 } & $\mathbf{x}$ & $\mathbf{y}$ & $\mathbf{z}$ & & \\
\hline $\mathrm{Pb}$ & 0.00000 & 0.00000 & 0.00000 & 0.34677 & 2.02 \\
$\mathrm{~S}$ & 0.50000 & 0.50000 & 0.50000 & -0.16415 & 2.00 \\
\hline
\end{tabular}

Hence, on the basis of the crystal unit cell parameters of the unknown stone, their coordinates and the peak positions at $2 \theta$ values and the structure of the molecule $\mathrm{PbS}$ elucidated by these two refinement software packages used in this study also in addition to the physical parameters, which are very essential to direct the study in this direction, the authors have concluded that this unknown stone could be only belonged to $\mathrm{PbS}$, Galena and nothing otherwise.

\section{Acknowledgements}

Dr. M. Baskar, Director, CFSL, Bhopal acknowledge Dr. R.S. Verma, former Director of CFSL, Chandigarh to have motivated the author to carry out such work on Gemstone identification and extended the instrumentation facility, Panalyti- 
cal X-PERT PRO, DY993 X-ray Powder Diffractometer, in the laboratory at CFSL, Chandigarh.

\section{Conflicts of Interest}

The authors declare no conflicts of interest regarding the publication of this paper.

\section{References}

[1] Holder, C.F. and Schaak, R.E. (2019) Tutorial on Powder X-Ray Diffraction for Characterizing Nanoscale Materials. ACS Nano, 7, 7359-7365.

https://doi.org/10.1021/acsnano.9b05157

[2] Chatterjee, P., Chakraborty, A. and Mukherjee, A.K. (2018) Phase Composition and Morphological Characterization of Human Kidney Stones Using IR Spectroscopy, Scanning Electron Microscopy and X-Ray Rietveld Analysis. Spectrochimica Acta Part A: Molecular and Biomolecular Spectroscopy, 200, 33-42. https://doi.org/10.1016/j.saa.2018.04.005

[3] Kondoh, J. (2004) Origin of the Hump on the Left Shoulder of the X-Ray Diffraction Peaks Observed in $\mathrm{Y}_{2} \mathrm{O}_{3}$-Fully and Partially Stabilized $\mathrm{ZrO}_{2}$. Journal of Alloys and Compounds, 375, 270-282. https://doi.org/10.1016/j.jallcom.2003.11.129

[4] Dinnebier, R.E. and Billlinge, S.J.L. (2008) Powder Diffraction: Theory and Practice. The Royal Society of Chemistry, Cambridge. https://doi.org/10.1039/9781847558237

[5] Smith, D.K. and Jenkins, R. (1996) The Powder Diffraction File: Past, Present, and Future. Journal of Research of the National Institute of Standards and Technology, 101, 259-271. https://doi.org/10.6028/jres.101.027

[6] Bish, D.L. and Howard, S.A. (1988) Quantitative Phase Analysis Using the Rietveld Method. Journal of Applied Crystallography, 21, 86-91. https://doi.org/10.1107/S0021889887009415

[7] Young, R.A. (1993) International Union of Crystallography. Oxford University Press, Oxford.

[8] Klug, H.P. and Alexander, L.E. (1974) X-Ray Diffraction Procedures-For Polycrystalline and Amorphous Materials. 2nd Edition, Wiley Interscience, Hoboken.

[9] Glusker, J.P. and Trueblood, K.N. (1985) Crystal Structure Analysis-A Primer. 2nd Edition, Oxford University Press, Oxford.

[10] Ford, R.G., Bertsch, P.M. and Seaman, J.C. (1997) Geothite Morphologies Investigated via X-Ray Diffraction of Oriented Samples. Clays and Clay Minerals, 45, 769-772. https://doi.org/10.1346/CCMN.1997.0450515

[11] Glusker, J.P., Lewis, M. and Rossi, M. (1994) Crystal Structure Analysis for Chemists and Biologists. 3rd Edition, Wiley, Hoboken.

[12] Dong, C. (1999) Powder X: Windows-95-Based Program for Powder X-Ray Diffraction Data Processing. Journal of Applied Crystallography, 32, 838. https://doi.org/10.1107/S0021889899003039

[13] Rodriguez-Carvajal, J. (2001) Recent Developments of the Program Fullprof, Newletter in Commission on Powder Diffraction (IUCr). Scientific Research, 26, 12-19. http://www.iucr-cpd.org/Newsletters.htm

[14] Toby, B.H. and Von Dreele, R.B. (2013) GSAS-II: The Genesis of a Modern Open-Source All Purpose Crystallography Software Package. Journal of Applied 
Crystallography, 46, 544-549. https://doi.org/10.1107/S0021889813003531

[15] Petricek, V., Dusek, M. and Palatinus, L. (2014) Crystallographic Computing System JANA2006: General Features. Zeitschrift für Kristallographie-Crystalline Materials, 229, 345-352. https://doi.org/10.1515/zkri-2014-1737

[16] Young, R.A., Sakthivel, A., Moss, T.S. and Paiva-Santos, C.O. (1995) DBWS-9411. An Upgrade of the DBWS. Programs for Rietveld Refinement with PC and Mainframe Computers. Journal of Applied Crystallography, 28, 366-367. https://doi.org/10.1107/S0021889895002160

[17] Hill, R.J. (1992) Rietveld Refinement Roun d Robin. I. Analysis of Standard X-Ray and Neutron Data for $\mathrm{PbSO}_{4}$. Journal of Applied Crystallography, 25, 589-610. https://doi.org/10.1107/S0021889892003649

[18] Izumi, F. and Momma, K. (2007) Three-Dimensional Visualization in Powder Diffraction. Solid State Phenomena, 130, 15-20. https://doi.org/10.4028/www.scientific.net/SSP.130.15

[19] Ida, T. and Izumi, F. (2012) Analytical Method for Observed Powder Diffraction Intensity Data Based on Maximum Likelihood Estimation. Advances in X-Ray Analysis, 56.

[20] Edgar, M., Carter, V.J., Tunstall, D.P., Grewal, P., Favre-Nicolin, V. and Cox, P.A. (2002) Structure Solution of a Novel Aluminium Methylphosphonate Using a New Simulated Annealing Program and Powder X-Ray Diffraction Data. Chemical Communications, 2002, 808-809. https://doi.org/10.1039/b200318j

[21] Henao, J.A., Delgado, J.M. and Quintero, M. (1997) X-Ray Powder Diffraction Data and Structural Study $\mathrm{Fe}_{2} \mathrm{GeSe}_{4}$. Powder Diffraction, 13, 196-201. https://doi.org/10.1017/S0885715600010101

[22] Noda, Y., Masumoto, K., Ohba, S., Saito, Y., Toriumi, K. and Shibuya, I.Y. (1987) Temperature Dependence of Atomic Thermal Parameters of Lead Chalcogenides, $\mathrm{PbS}, \mathrm{PbSe}$ and PbTe. Acta Crystallographica, C43, 1443-1445. https://doi.org/10.1107/S0108270187091509

[23] Coppens, P., Guru Row, T.N., Leung, P., Stevens, E.D., Becker, P.J. and Yang, Y.W. (1979) Temperature Dependence of Atomic Thermal Parameters of Lead Chaleogenides, $\mathrm{PbS}, \mathrm{PbSe}$ and PbTe. Acta Crystallographica, A35, 63-72. https://doi.org/10.1107/S0567739479000127

[24] Crystallographic Open Database. http://www.crystallography.net/cod/

[25] Fosu, S., Pring, A., Skinner, W. and Zanin, M. (2013) Synthesis of Galena (PbS) in Silica Gel Composite Particles by Sulphidisation and Hydrothermal Reaction. Engineers Australia, 454-458.

https://search.informit.com.au/documentSummary; dn = 882199212739952

[26] Boultif, A. and Louer, D. (2004) Powder Pattern Indexing with the Dichotomy Method. Journal of Applied Crystallography, 37, 724-731.

https://doi.org/10.1107/S0021889804014876 